\title{
Distress of Routine Activities and Perceived Safety Associated with Post-Traumatic Stress, Depression, and Alcohol Use: 2002 Washington, DC, Sniper Attacks
}

\author{
Carol S. Fullerton, PhD; Holly B. Herberman Mash, PhD; K. Nikki Benevides, MA; \\ Joshua C. Morganstein, MD; Robert J. Ursano, MD
}

\section{ABSTRACT}

Objective: For over 3 weeks in October 2002, a series of sniper attacks in the Washington, DC, area left 10 people dead and 3 wounded. This study examined the relationship of distress associated with routine activities and perceived safety to psychological and behavioral responses.

Methods: Participants were 1238 residents of the Washington, DC, metropolitan area (aged 18 to 90 years, mean $=41.7$ years) who completed an Internet survey including the Impact of Event Scale-Revised, Patient Health Questionnaire-9, and items pertaining to distress related to routine activities, perceived safety, and alcohol use. Data were collected at one time point approximately 3 weeks after the first sniper shooting and before apprehension of the suspects. Relationships of distress and perceived safety to posttraumatic stress, depressive symptoms, and increased alcohol use were examined by using linear and logistic regression analyses.

Results: Approximately $8 \%$ of the participants met the symptom criteria for probable post-traumatic stress disorder, 22\% reported mild to severe depression, and 4\% reported increased alcohol use during the attacks. Distress related to routine activities and perceived safety were associated with increased posttraumatic stress and depressive symptoms and alcohol use.

Conclusion: Distress and perceived safety are associated with specific routine activities and both contribute to psychological and behavioral responses during a terrorist attack. These findings have implications for targeted information dissemination and risk communication by community leaders. (Disaster Med Public Health Preparedness. 2015;9:509-515)

Key Words: terrorism, stress disorders, post-traumatic, mental disorders, perceived safety

$\mathrm{T}$ errorist events can produce considerable psychological distress and functional impairment and may be associated with responses including post-traumatic stress disorder (PTSD), depression, and health risk behaviors, such as increased alcohol and substance use. ${ }^{1-4}$ For more than 3 weeks in October 2002, a series of sniper attacks in the Washington, DC, metropolitan area left 10 people dead and 3 others wounded. The shooting victims varied in age (ranging from 13 to 72 years), sex, race, and by occupation. The shootings occurred at different times of the day and in various public areas (eg, gas stations, bus stops, shopping mall parking lots, and outside a middle school entrance), which prevented community residents from identifying a pattern in the shootings. Because it was not possible to identify the location of the shooter during the attacks, because the shootings occurred at a distance, many outdoor activities were cancelled. Few empirical studies have investigated the immediate impact of this type of sustained community-wide terrorist event, and, to our knowledge, no studies have empirically examined the community response to the Washington, DC, sniper attacks.

Individuals exposed to terrorist attacks can experience high rates of PTSD and depression, ${ }^{5-8}$ which can remain elevated for years after the event. ${ }^{2,8-9}$ Exposure to terrorist attacks is also associated with an increase in health risk behaviors, such as cigarette, alcohol, and drug use. ${ }^{10}$ Among New York City residents, 9.7\%, 24.6\%, and 3.2\% reported increases in smoking, alcohol use, and marijuana use, respectively, 1 to 2 months after $9 / 11 .^{3}$ Six percent of New York City residents reported increased alcohol use 1 year after $9 / 11$, and $12 \%$ reported an increase in alcohol use 1 to 2 years after the attacks. ${ }^{11}$

The perception of safety during and following a traumatic event is associated with psychological and 
behavioral functioning. ${ }^{12-14}$ Studies conducted after $9 / 11$ that examined risk appraisal for future attacks found that $40 \%$ to $50 \%$ of individuals reported elevated safety concerns. ${ }^{1,15}$ Survivors of the 9/11 attack on the Pentagon who reported lower perceived safety were more likely to have probable PTSD and to report increased alcohol use 7 months after the event. $^{16}$

Few empirical studies have examined responses to the DC sniper attacks. A study of local hospital staff found that $6 \%$ met the criteria for probable acute stress disorder, $8 \%$ had depression, and 3\% reported increased alcohol use 1 week after the event. ${ }^{17}$ Seven months after the sniper attacks, $7 \%$ of community residents met the criteria for PTSD. ${ }^{18}$ In a study of homeless individuals in Washington, DC, $41 \%$ reported increased substance use during the attacks. ${ }^{19}$ To better understand community responses to the DC sniper attacks, this study examined the relationship of distress related to routine activities and perceived safety to post-traumatic stress, depressive symptoms, and increased alcohol use.

\section{METHODS}

\section{Participants and Procedures}

Participants were 1238 residents living in the Washington, DC, metropolitan area during the sniper attacks in October 2002. Participants ranged in age from 18 to 90 years (mean $=41.7$ years; $S D=12.56)$. Approximately half of the sample was female $(51 \% ; n=636)$ and had earned a bachelor's or graduate degree $(50.1 \% ; n=621)$ (Table 1$)$. The majority of the participants were employed $(79 \%$; $n=978)$, were married $(57 \% ; n=707)$, were white $(68 \%$; $n=847)$, and had children ( $58 \% ; n=724)$. Approximately $47 \%(n=559)$ of the participants lived within 20 miles of downtown Washington, DC; 34\% $(n=406)$ lived within 21 to 50 miles; $10 \%(n=123)$ lived within 51 to 100 miles; and $9 \%(n=112)$ lived over 100 miles from the city.

Participants were recruited from a group of approximately 40,000 Washington, DC, area residents who subscribed to the NetZero Internet service provider (ISP) and indicated interest in participating in survey research. The NetZero ISP was available to the general public and was provided for no charge at the time of the sniper attacks, potentially allowing for access from a representative sample of community residents. The lead author (CSF) arranged through NetZero for the online survey to be available to the pool of subscribers who expressed interest in participation in survey research.

Data were collected at one time point approximately 3 weeks after the first sniper shooting and prior to apprehension of the suspects. Potential participants were contacted via e-mail to assess interest in participating in the study. They were informed that participation would be voluntary and anonymous. Information regarding the survey was provided in a written format. Individuals indicated consent by filling out

\begin{tabular}{|c|c|}
\hline \multicolumn{2}{|c|}{ Demographics of the Participants ${ }^{a}$} \\
\hline Demographics & N (\%) \\
\hline \multicolumn{2}{|l|}{ Sex } \\
\hline Male & $602(49)$ \\
\hline Female & $636(51)$ \\
\hline \multicolumn{2}{|l|}{ Ethnicity } \\
\hline White & $847(68)$ \\
\hline Nonwhite & $391(32)$ \\
\hline \multicolumn{2}{|l|}{ Marital Status } \\
\hline Not married & $531(43)$ \\
\hline Married & 707 (57) \\
\hline \multicolumn{2}{|l|}{ Employment Status ${ }^{b}$} \\
\hline Not employed & $254(21)$ \\
\hline Employed & $978(79)$ \\
\hline \multicolumn{2}{|l|}{ Has children } \\
\hline Yes & $724(58)$ \\
\hline No & $514(42)$ \\
\hline \multicolumn{2}{|l|}{ Age, years } \\
\hline Mean (SD) & $41.73(12.56)$ \\
\hline Range & $18-90$ \\
\hline \multicolumn{2}{|c|}{ Distance of home from DC } \\
\hline 0-20 miles & $559(47)$ \\
\hline 21-50 miles & $406(34)$ \\
\hline $51-100$ miles & $123(10)$ \\
\hline Over 100 miles & $112(9)$ \\
\hline Mean (SD) & $45(58.5)$ \\
\hline
\end{tabular}

the survey and returning it via anonymous transmission. Participants were informed that the survey included questions about their health, lifestyle, current feelings, and health practices and would take approximately 10 minutes to complete. The study was approved by the Institutional Review Board of the Uniformed Services University of the Health Sciences in Bethesda, Maryland.

\section{Measures}

Participants completed an online self-report questionnaire that included 5 sections (71 total items): sociodemographic characteristics; psychological responses during the attacks; current psychological, social, and behavioral functioning (including post-traumatic stress symptoms, depressive symptoms, and alcohol use); perceptions of the environment (eg, feelings of safety); and recent behavioral changes (including alcohol use and health service use). This study specifically focused on demographic characteristics, feelings of distress related to routine activities, perception of safety, and psychological and behavioral responses to the sniper attacks.

\section{Distress Related to Routine Activities}

The impact of the sniper attacks on the participants' distress about performing routine activities was measured by items 
that were based on circumstances surrounding the actual shootings that occurred. The following items were assessed on a 5-point scale ranging from 0 (none) to 4 (extreme): (1) being in large public places (eg, shopping malls), (2) getting gas, (3) sending one's child or children to school and activities, (4) attending large public gatherings (eg, concerts or sporting events), (5) traveling by public transportation, (6) traveling by auto, and (7) attending faith-based activities.

\section{Perceived Safety}

Three items assessed whether participants currently felt safe at work, in their homes, and in general throughout the day during their usual activities and travel. Participants rated their level of perceived safety for each of these 3 categories on a 5 -point Likert scale ranging from 0 (not at all) to 4 (extremely).

\section{Post-Traumatic Stress}

Post-traumatic stress symptom severity was assessed with the Impact of Event Scale-Revised (IES-R). ${ }^{20}$ The IES-R is a 22-item self-report measure that includes subscales that categorize symptoms of intrusion, avoidance, and hyperarousal. Participants reported the extent to which they were distressed or bothered by symptoms over the past week on a scale ranging from 0 (not at all) to 4 (extremely). Responses were summed to produce symptom severity scores ranging from 0 to 88 . Probable PTSD was identified by scores of 33 or greater, ${ }^{21}$ taking into account the assessment period at approximately 3 weeks following the first sniper attack. The IES-R has been found to exhibit high internal consistency for the total scale (Cronbach's alpha $=0.96)^{21}$ as well as the intrusion, avoidance, and hyperarousal subscales (coefficient alphas ranging from 0.87 to 0.92 ). ${ }^{20}$

\section{Depression}

Depression symptom severity was assessed with the 9-item Patient Health Questionnaire-Depression Scale (PHQ-9). ${ }^{22}$ The PHQ-9 is a self-report measure that assesses the frequency of each of the DSM-IV (Diagnostic and Statistical Manual of Mental Disorders, 4th edition) Major Depressive Episode Criterion A symptoms during the past 2 weeks on a scale ranging from 0 (not at all) to 3 (nearly every day). Responses are summed to produce depressive symptom severity scores ranging from 0 to 27 . Scores of 5 or greater on the PHQ-9 indicate mild to severe depression. ${ }^{22}$ When compared against structured clinical evaluations in primary care settings, the PHQ-9 demonstrated $73 \%$ sensitivity and 94\% specificity. ${ }^{22,23}$ The PHQ-9 has high internal and testretest reliability ( $\alpha=0.89$ and $r=0.84$, respectively).

\section{Increase in Alcohol Use}

Alcohol use was assessed by participants' responses to a single yes/no item that identified whether alcohol use had increased for a period of 2 weeks or more since the beginning of the sniper attacks.

\section{Statistical Analyses}

Prevalence rates of probable PTSD, mild to severe depression, and increased alcohol use at 3 weeks, as well as mean levels of post-traumatic stress and depressive symptoms were identified by using descriptive statistics. Chi-square analyses, analyses of variance, and bivariate correlations were conducted to assess whether there were significant demographic differences among the psychological and behavioral response groups. For cases in which differences were found, these background variables were included in further analyses as covariates. Hierarchical linear regression analyses were conducted to examine the extent to which level of distress associated with engaging in routine activities and feelings of safety (at home, at work, and in general) were related to post-traumatic stress and depressive symptoms. Logistic regression analysis was performed to investigate the relationship of distress and safety to increase in alcohol use. Odds ratios were defined as the likelihood of experiencing increased alcohol use for individuals with or without a risk factor (ie, distress about routine activities and perceived safety). The estimate of the odds ratio and its $95 \%$ confidence interval (CI) are reported. The Wald chi-square $\left(\chi^{2}\right)$ test was used to determine if there was any significant difference between the odds for individuals with versus without a risk factor. Statistical analyses were conducted by using SPSS Statistics 22. ${ }^{24}$

\section{RESULTS}

Approximately $8 \%$ of the participants $(n=93)$ met the symptom criteria for probable PTSD, 22\% $(n=268)$ reported mild to severe depression, and $4 \%(n=46)$ reported an increase in alcohol use in the initial 2-week period during the sniper attacks. Approximately one-third $(31.3 \% ; n=381)$ had either probable PTSD, mild to severe depression, or increased alcohol use. Seven percent $(n=84)$ reported both probable PTSD and depression, 3.4\% $(n=30)$ reported both depression and increased alcohol use, $1.1 \%(n=12)$ reported both probable PTSD and increased alcohol use, and 0.9\% $(n=11)$ reported all 3 responses (Figure 1). Eighty-eight percent $(n=1050)$ reported distress about participating in one or more routine activities, and $71.7 \%(n=885)$ reported moderate to extreme distress related to at least one activity. Getting gas and being in large public places were associated with the highest levels of distress (mean $=1.95, \mathrm{SD}=1.40$; and mean $=1.74, \mathrm{SD}=1.29$, respectively), and attending faith-based activities was associated with the lowest levels of distress (mean $=0.79, \mathrm{SD}=1.18)$.

\section{Post-Traumatic Stress Symptoms, Routine Activities, and Safety}

The relationship of distress related to routine activities and perceived safety to post-traumatic stress symptoms, with adjustment for demographics and proximity to DC, was examined by using hierarchical linear regression analyses. The final model is shown in Table 2. Age, sex, and marital and 


\section{FIGURE 1}

\section{Probable Post-Traumatic Stress Disorder (PTSD), Mild to Severe Depression, and Increase in Alcohol Use Prevalence.}

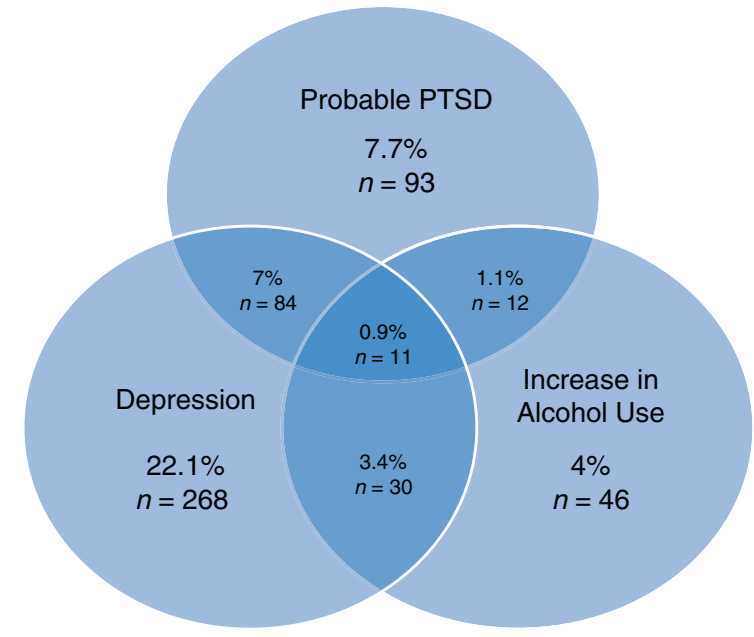

Participants were 1238 residents of the Washington, DC, metropolitan area who completed an Internet survey after the DC sniper attacks in 2002.

parental status were entered on the first step and accounted for $3.6 \%$ of the variance in post-traumatic stress symptoms (sex: $\beta=3.495, \quad P<0.001$; marital status: $\beta=-2.715$, $P=0.003)$, indicating that those who were female and unmarried reported more post-traumatic stress symptoms. Addition of proximity from Washington, DC, in the model did not produce significant effects $(\beta=-0.006, P=0.336$, $\left.\Delta \mathrm{R}^{2}=0.001\right)$. Inclusion of distress items accounted for an additional $17.7 \%$ of the variance, with distress related to sending children to school or activities $(\beta=0.954$, $P=0.004)$, attending large public gatherings $(\beta=1.495$, $P=0.001)$, and traveling by auto $(\beta=0.995, P 0.035)$ associated with higher levels of post-traumatic stress. Perceived safety at work, at home, and in general accounted for an additional $4.4 \%$ of the variance in this model $(\beta=-1.272$, $P=0.01 ; \beta=-1.186, P=0.034 ; \beta=-1.585, P=0.003$, respectively), with lower levels of safety associated with higher levels of post-traumatic stress symptoms.

\section{Depressive Symptoms, Routine Activities, and Safety}

The relationship of distress associated with routine activities and perceived safety to symptoms of depression, with adjustment for demographics and proximity to DC, were also examined by using hierarchical linear regression analyses. The final model is shown in Table 2. Demographic variables were entered on the first step and accounted for $4.8 \%$ of the variance in depression, with participants who were younger $(\beta=-0.043, P=0.001)$, female $(\beta=1.056, P<0.001)$, and unmarried $(\beta=-1.122, P=0.001)$ reporting more depressive symptoms. Addition of proximity from DC in the model did not significantly improve the model $(\beta=0.002$, $\left.P=0.400, \quad \Delta R^{2}=0.001\right)$. Inclusion of distress items accounted for an additional $9.3 \%$ of the variance in depressive symptoms. Specifically, distress related to traveling by public transportation $(\beta=0.412, P=0.003)$ and traveling by auto $(\beta=0.633, P<0.001)$ were associated with higher levels of depression. Perceived safety at work, at home, and safety in general accounted for an additional $4.4 \%$ of the variance. Lower perceived safety at home $(\beta=-0.423$, $P=0.044)$ and general safety $(\beta=-0.756, P<0.001)$ were individually associated with higher depressive symptoms.

\section{Increased Alcohol Use, Routine Activities, and Safety}

The relationship of distress associated with routine activities and perceived safety to increased alcohol use was examined by using multivariate logistic regression analyses (Table 3). Demographic variables were entered on the first step of the model, followed by proximity to DC, but these variables did not significantly predict risk of increased alcohol use. After adjustment for demographics and proximity to DC, there continued to be a significant relationship of distress about traveling by automobile and perceived safety at home to increased alcohol use $\left(\chi^{2}=4.889, P=0.027\right.$; and $\chi^{2}=3.834, P=0.05$, respectively). Specifically, those who reported distress about traveling by auto were 1.51 times as likely to increase their alcohol use (95\% CI: 1.048-2.173, P = 0.027), and those who felt less safe at home were more likely to increase their alcohol use (odds ratio $=0.660 ; 95 \% \mathrm{CI}: 0.436-1.00 ; P=0.05$ ). Distress and perceived safety about other types of routine activities were not associated with increased alcohol use.

\section{DISCUSSION}

The primary goals of terrorist acts are to instill feelings of intense fear and loss of safety and perceived control over one's environment. ${ }^{25}$ The seeming randomness of terrorist acts such as the sniper attacks can affect individuals' perception of control, resulting in distress about routine activities and avoidant behaviors. Approximately one-third of the participants in our study had probable PTSD, mild to severe depression, or increased alcohol use during the sniper attacks. The prevalence rates of probable PTSD (7.7\%) and mild to severe depression $(22 \%)$ identified in this study were relatively higher than those found in the US adult population during the same time period. The current year and lifetime prevalence rates of PTSD in the US population between February 2001 and April 2003 were identified as 3.5\% and $6.8 \%$, respectively, ${ }^{26,27}$ and rates of depression ranged between $6.6 \%$ and $7.06 \%$ during the time period that the sniper attacks occurred. ${ }^{28,29}$

In this study, women and unmarried participants reported higher levels of post-traumatic stress and depressive symptoms, and younger participants reported higher levels of depressive symptoms. Higher post-traumatic stress in women 


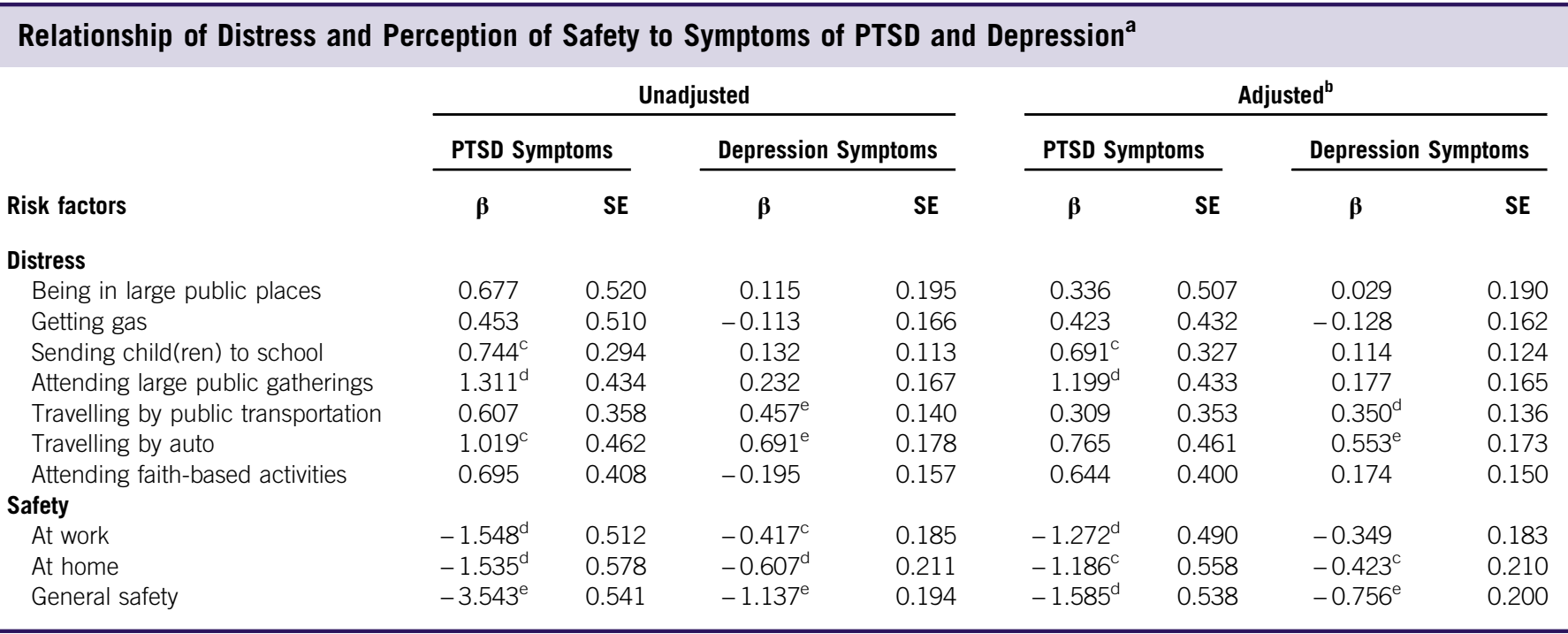

${ }^{a}$ Abbreviation: PTSD, post-traumatic stress disorder.

${ }^{\mathrm{b}}$ Adjusted for age, sex, marital and parental status, and proximity to DC. Variables in the full model accounted for $25.7 \%$ of the variance in PTSD and $18.5 \%$ of the variance in depression.

${ }^{c} p \leq 0.05$.

${ }^{\mathrm{d}} \mathrm{p} \leq 0.01$.

${ }^{\mathrm{e}} \mathrm{p} \leq 0.001$

\section{TABLE 3}

\section{Relationship of Distress and Perceptions of Safety to Increase in Alcohol Use}

\begin{tabular}{|c|c|c|c|c|c|c|c|c|}
\hline \multirow[b]{2}{*}{ Risk Factors } & \multicolumn{4}{|c|}{ Unadjusted } & \multicolumn{4}{|c|}{ Adjusted $^{\mathrm{b}}$} \\
\hline & $\mathbf{O R}$ & $(95 \% \mathrm{CI})$ & $\chi^{2}$ & $P$ & OR & $(95 \% \mathrm{CI})$ & $\chi^{2}$ & $P$ \\
\hline \multicolumn{9}{|l|}{ Distress } \\
\hline Being in large public places & 0.974 & $(0.641-1.480)$ & .015 & 0.903 & 0.950 & $(0.627-1.440)$ & 0.058 & 0.810 \\
\hline Getting gas & 1.066 & $(0.744-1.527)$ & 0.122 & 0.727 & 1.018 & $(0.710-1.461)$ & 0.010 & 0.921 \\
\hline Traveling by public transportation & 0.916 & $(0.705-1.190)$ & 0.431 & 0.512 & 0.816 & (0.618-1.078) & 2.052 & 0.152 \\
\hline Traveling by auto & 1.469 & $(1.032-2.091)$ & 4.547 & 0.033 & 1.509 & $(1.048-2.173)$ & 4.889 & 0.027 \\
\hline Attending faith-based activities & 0.997 & $(0.747-1.331)$ & 0.000 & 0.985 & 1.015 & $(0.759-1.358)$ & 0.010 & 0.920 \\
\hline \multicolumn{9}{|l|}{ Safety } \\
\hline At work & 0.811 & $(0.560-1.176)$ & 1.217 & 0.270 & 0.748 & $(0.515-1.087)$ & 2.319 & 0.128 \\
\hline At home & 0.630 & $(0.414-0.957)$ & 4.684 & 0.030 & 0.660 & $(0.436-1.000)$ & 3.834 & 0.050 \\
\hline
\end{tabular}

${ }^{a}$ Abbreviations: $\mathrm{Cl}$, confidence interval; OR, odds ratio.

${ }^{\mathrm{b}}$ Adjusted for age, sex, marital and parental status, and proximity to DC.

in this sample is comparable to the increased risk of probable PTSD found in women exposed to the $9 / 11$ attack on the Pentagon. ${ }^{16}$ Being female, younger, and unmarried have been identified as risk factors for acute stress disorder in individuals exposed to terrorist events and disasters. ${ }^{30,31}$ The social support that spouses provide may be particularly effective in buffering stress and can decrease adverse psychological responses during and following trauma exposure. ${ }^{32-34}$
Distress related to one's routine activities was associated with increased post-traumatic stress, depressive symptoms, and alcohol use. Importantly, after controlling for demographics and proximity to DC, and looking across the different domains of distress, distress related to sending children to school and attending large public gatherings continued to be associated with increased post-traumatic stress symptoms. In particular, those who reported distress about traveling by 
public transportation or automobile experienced more depressive symptoms, and distress about automobile travel was also associated with increased alcohol use. Therefore, attending to specific areas of distress can be important to planning by community leaders. By investigating circumstances associated with the sniper attacks, we found specific routine activities that could be directly addressed in risk communications and protective community actions.

Participants who experienced lower general safety throughout the day and/or reduced safety at work or home had greater posttraumatic stress symptoms. A similar relationship was found between lower perceived safety and PTSD 7 months after the $9 / 11$ attack on the Pentagon ${ }^{16}$ and in Iraqi civilians exposed to terrorist bombings. ${ }^{35}$ Decreased safety at home and general safety throughout the day were also associated with higher levels of depression in the current study. Lower perceived safety at home was also related to increased alcohol use. Participants who believed that their safety was threatened even at home may have used alcohol to manage their distress. ${ }^{36-40}$

Interpretation of the study findings is limited by its crosssectional design. Longitudinal assessment after the capture of the snipers would provide additional information regarding the trajectory of trauma response. Assessment of participants at least 1 month after the first sniper attack would allow for examination of symptoms that met the DSM-IV PTSD 1-month duration criterion. However, study of participants before the apprehension of the snipers provided valuable information regarding responses during the ongoing event. Participants agreed to participate in online surveys through the NetZero Internet service, thus limiting the generalizability of results. Determination of accurate response rates to online survey administration is complicated by several factors, including limited information regarding how many surveys were successfully received, the number of e-mails that were opened by potential participants, and whether those individuals attempted to access the survey. Although previous research has found demographic biases when using online survey administration, ${ }^{41-44}$ demographic variables were controlled for in the analyses of this study and did not affect the outcomes. Study findings were limited by the use of self-report measures.

\section{CONCLUSIONS}

The results of this study identify individuals who may be at risk of depressive and post-traumatic stress symptoms and increased alcohol use during a terrorist event. Importantly, distress about specific routine activities is associated with more psychological symptoms. Attending to these responses can be an important target for community leaders. In addition, perceived safety contributed to mental and behavioral health outcomes even after adjustment for distress. Therefore, it is important for disaster communication strategies to target safety as well as distress-related areas. The widespread community impact of a terrorist event such as the DC sniper attacks highlights the importance of developing early interventions for at-risk groups, such as women, younger individuals, and those who are unmarried and may not have a stable support system.

\section{About the Authors}

Center for the Study of Traumatic Stress, Department of Psychiatry, Uniformed Services University of the Health Sciences, Bethesda, Maryland.

Correspondence and reprint requests to Holly B. Herberman Mash, Uniformed Services University of the Health Sciences, Department of Psychiatry, 4301 Jones Bridge Road, Bethesda, MD 20814 (e-mail:holly.herberman-mash.ctr@usuhs.edu).

Published online: June 5, 2015.

\section{REFERENCES}

1. Silver RC, Holman EA, McIntosh DN, et al. Nationwide longitudinal study of psychological response to September 11. J Am Med Assoc. 2002;288:1235-1244.

2. Henriksen CA, Bolton JM, Sareen J. The psychological impact of terrorist attacks: examining a dose-response relationship between exposure to $9 / 11$ and Axis I mental disorders. Depress Anxiety. 2010;27:993-1000.

3. Vlahov D, Galea S, Resnick H, et al. Increased use of cigarettes, alcohol, and marijuana among Manhattan, New York residents after the September $11^{\text {th }}$ terrorist attacks. Am J Epidemiol. 2002;155(11):988-996.

4. Vlahov D, Galea S, Resnick H, et al. Consumption of cigarettes, alcohol, and marijuana among New York City residents six months after the September 11 terrorist attacks. Am J Drug Alcohol Abuse. 2004; 30(2):385-407.

5. Ferrando L, Galea S, Corton ES, et al. Long-term psychopathological changes among the injured and members of the community after a massive terrorist attack. Eur Psychiatry. 2011;26(8):513-517.

6. Gabriel R, Ferrando L, Corton ES, et al. Psychopathological consequences after a terrorist attack: an epidemiological study among victims, the general population, and police officers. Eur Psychiatry. 2007;22:339-346.

7. Miguel-Tobal JJ, Cano-Vindel A, Gonzalez-Ordi H, et al. PTSD and depression after the Madrid March 11 train bombings. J Trauma Stress. 2006;19(1):69-80.

8. North CS, Nixon SJ, Shariat S, et al. Psychiatric disorders among survivors of the Oklahoma City bombing. J Am Med Assoc. 1999; 282(8):755-762.

9. Zhang G, North CS, Narayanan P, et al. The course of postdisaster psychiatric disorders in directly exposed civilians after the US Embassy bombing in Nairobi, Kenya: a follow-up study. Soc Psychiatry Psychiatr Epidemiol. 2013;48(2):195-203.

10. DiMaggio C, Galea S, Guohua L. Substance use and misuse in the aftermath of terrorism. A Bayesian approach. Addiction. 2009;104: 894-904.

11. Boscarino JA, Adams RE, Galea S. Alcohol use in New York after the terrorist attacks: a study of the effects of psychological trauma on drinking behavior. Addict Behav. 2006;31:606-621.

12. Ursano RJ, Fullerton CS, Norwood AE, eds. Planning for Bioterrorism: Behavior and Mental Health Responses to Weapons of Mass Destruction and Mass Disruption. Bethesda, MD: Defense Technical Information Center (available from authors on request); 2001.

13. Ursano RJ. Post-traumatic stress disorder. $N$ Engl J Med. 2002;346:130-132.

14. Marshall RD, Bryant RA, Amsel L, et al. The psychology of ongoing threat: relative risk appraisal, the September 11 attacks, and terrorismrelated fears. Am Psychol. 2007;62(4):304-316.

15. Torabi MR, Seo DC. National study of behavioral and life changes since September 11. Health Educ Behav. 2004;31:179-192. 
16. Grieger TA, Fullerton CS, Ursano RJ. Posttraumatic stress disorder, alcohol use, and perceived safety after the terrorist attack on the Pentagon. Psychiatr Serv. 2003;54(10):1380-1382.

17. Grieger TA, Fullerton CS, Ursano RJ, et al. Acute stress disorder, alcohol use, and perception of safety among hospital staff after the sniper attacks. Psychiatr Serv. 2003;54(10):1383-1387.

18. Schulden J, Chen J, Kresnow M-J, et al. Psychological responses to the sniper attacks: Washington, D.C. area, October 2002. Am J Prev Med. 2006;31(4):324-327.

19. Fullerton CS, Gifford RK, Flynn BW, et al. Effects of the 2002 sniper attacks on the homeless population in Washington, D.C. Disaster Med Public Health Prep. 2009;3(3):163-167.

20. Weiss DS, Marmar CR. The Impact of Event Scale- Revised. In: Wilson JP, Keane TM, eds. Assessing Psychological Trauma and PTSD: A Practitioner's Handbook. New York: Guilford Press; 1997:399-411.

21. Creamer M, Bell R, Failla S. Psychometric properties of the Impact of Event Scale-Revised. Behav Res Ther. 2003;41:1489-1496.

22. Kroenke K, Spitzer RL, Williams JBW. The PHQ-9: Validity of a brief depression measure. J Gen Intern Med. 2001;16:606-613.

23. Spitzer RL, Kroenke K, Williams JBW. Validity and utility of a selfreport version of PRIME-MD: The PHQ Primary Care Study. J Am Med Assoc. 1999;282:1737-1744.

24. IBM Corp. IBM SPSS Statistics for Windows, version 22.0. Armonk, NY: IBM Corp; 2013

25. Fullerton CS, Ursano RJ, Norwood A. Planning for the psychological effects of bioterrorism. In: Ursano RJ, Norwood AE, Fullerton CS, eds. Bioterrorism: Psychological and Public Health Interventions. Cambridge, United Kingdom: Cambridge University Press; 2004:2-14.

26. Kessler RC, Berglund P, Demler O, et al. Lifetime prevalence and age-ofonset distributions of DSM-IV disorders in the National Comorbidity Survey Replication. Arch Gen Psychiatry. 2005;62(6):593-602.

27. Kessler RC, Chiu WT, Demler O, et al. Prevalence, severity, and comorbidity of 12 -month DSM-IV disorders in the National Comorbidity Survey Replication. Arch Gen Psychiatry. 2005; 62(6):617-627.

28. Kessler RC, Berglund R, Demler O, et al. The epidemiology of major depressive disorder: results from the National Comorbidity Survey Replication (NCS-R). J Am Med Assoc. 2003;289(13):3095-3105.

29. Compton WM, Conway KP, Stinson FS, et al. Changes in the prevalence of major depression and comorbid substance use disorders in the United States between 1991-1992 and 2001-2002. Am J Psychiatry. 2006;163(12):2141-2147.

30. Balasinorwala VP, Shah N. Acute stress disorder in victims after terror attacks in Mumbai, India. Br J Psychiatry. 2009;195:462.

31. Fullerton CS, Ursano RJ, Wang L. Acute stress disorder, posttraumatic stress disorder, and depression in disaster or rescue workers. Am J Psychiatry. 2004;161(8):1370-1376.

32. Charuvasta A, Cloitre M. Social bonds and posttraumatic stress disorder. Annu Rev Psychol. 2008;59:301-328.

33. Kawachi I, Berkman LF. Social ties and mental health. J Urban Health. 2001;78(3):458-467.

34. Kessler RC, Price RH, Wortman C. Social factors in psychopathology: Stress, social support, and coping processes. Annu Rev Psychol. 1985;36:531-572.

35. Freh FM, Chung MC, Dallos R. In the shadow of terror: posttraumatic stress and psychiatric co-morbidity following bombing in Iraq: the role of shattered world assumptions and altered self-capacities. J Psychiatr Res. 2013;47(2):215-225.

36. Hasin DS, Keyes KM, Hatzenbueler ML, et al. Alcohol consumption and posttraumatic stress after exposure to terrorism: effects of proximity, loss, and psychiatric history. Am J Public Health. 2007;97:2268-2275.

37. Levenson RW, Sher K, Grossman L, et al. Alcohol and stress response dampening: Pharmacological effects, expectancy, and tension reduction. J Abnorm Psychol. 1980;89:528-538.

38. Wills TA, Shiffman S. Coping and substance use: a conceptual framework. In: Shiffman S, Wills TA, eds. Coping and Substance Use. Orlando, FL: Academic Press; 1985:3-24.

39. Cooper ML, Russell M, Skinner JB, et al. Development and validation of a three-dimensional measure of drinking motives. Psychol Assess. 1992; $4(2): 123-132$.

40. Stewart SH. Alcohol abuse in individuals exposed to trauma: a critical review. Psychol Bull. 1996;120(1):83-112.

41. Sax LJ, Gilmartin SK, Bryant AN. Assessing response rates and nonresponse bias in web and paper surveys. Res High Educ. 2003;44(4):409-432.

42. Palmquist J, Steuve A. Stay plugged into new opportunities. Mark Res Mag Manage Appl. 1996;8:13-15.

43. Kehoe CM, Pitkow JE. Surveying the territory: GVU's five WWW user surveys. W3J. 1996;1:77-84.

44. Smith MA, Leigh B. Virtual subjects: using the Internet as an alternative source of subjects and research environment. Behav Res Methods Instrum Comput. 1997;29:496-505. 